\title{
Problemas Básicos da Administração da Universidade
}

V. Merikosky

\section{${ }^{66} \mathrm{~A}$}

autonomia da Universidade, seu Sentido Hoje", foi o tema central de discussão na Quarta Conferência Geral da Associação Internacional de Universidades, realizada em Tóquio em setembro de 1965. A matéria tinha sido cuidadosamente preparada com antecedência por iniciativa dos setores administrativos da Associação. Já em 1962, a Equipe Administrativa da Associação decidiu pedir ao Sr. Hector Hetherington, um dos mais experimentados Vice-Chanceleres do Reino Unido, que preparasse para sua consideração um memorando sôbre a Autonomia Universitária. Este memorando, com comentários feitos pelos membros da Equipe Administrativa, assim como com uma introdução feita pelo então Presidente da Associação, Dr. F. Cyrrill James, tinha sido impresso e pôsto à disposição dos participantes da conferência. (1) As discussões na conferência foram brilhantes, de alto gabarito, e elucidaram diferentes pontos-de-vista da matéria.

Devido à quase explosiva fase de desenvolvimento que a expansão da instrução universitária sofreu em todo o mundo durante os cinco anos passados, os problemas da administração universitária despertam uma atenção mais ampla do que apenas a dos círculos acadêmicos. Como na conferência de Tóquio eu tive a honra de atuar como repórter sôbre a questão da autonomia, introduzirei, nas páginas seguintes, algum material colhido na conferência.

(1) "A Autonomia da Universidade, seu Sentido Hoje." Periódico da Associação Internacional de Universidades, $\mathrm{n}^{0}$ 7, pág. 139, Paris, 1965. A edição francesa intitula-se «L'Autonomie universitaire - sa signification aujourd'hui." 
Usá-lo-lei livremente e sem ulteriores notas ao pé da página. (2)

Incluirei minhas próprias idéias, e mostrarei como os princípios da administração geral se aplicam à administração universitária em particular. Tratarei também de algumas questões básicas da administração universitária que ficaram fora do tema da conferência de Tóquio.

\section{I - A POSIÇÃO ADMINISTRATIVA E AS FORMAS DE ORGANIZAÇÃO DAS UNIVERSIDADES}

\section{A. CONCEITOS INDEFINIDOS}

Antes de começar a descrever as categorias principais em que as universidades podem ser divididas administrativamente, considero necessário fazer alguns comentários sôbre têrmos e conceitos que serão usados no artigo seguinte.

Devido às circunstâncias diferentes nos vários países, o conceito de "universidade" não pode ser definido num sentido universal e, ao mesmo tempo, de modo exato. Mas em todo caso os sinais característicos das universidades são que elas são instituiçôes superiores que combinam ensino e pesquisa, destinadas a servir um número bastante grande de estudantes. Considerando a finalidade dêste artigo, não parece necessário pretender uma definição mais especifica do que esta. Será suficiente operar dentro do conceito usado geralmente, embora um tanto impreciso.

A autonomia, que será discutida adiante mais plenamente, também permanece como um conceito controvertido sem uma definição geralmente aceita. Neste artigo êste têrmo será usado para significar o direito muito extenso que o Estado garante a uma comunidade subordinada, corporação, ou algum outro organismo para conduzir, através de seus próprios órgãos, aquêles assuntos, pertinentes a elas, para as quais o Estado não encon. trou outras soluções.

Esta definição não é de forma alguma exata. Um critério vago é - entre outros - o de "seus próprios órgãos."

Aquêles organizadores pela própria organização são claramente tais, mas a opinião geral é que mesmo as corporações em que o Estado participa para estruturar seus órgãos podem ser

(2) Os resumos da conferência foram publicados em 1966: "Relação da Quarta Conferência da Associação Internacional de Universidades", Paris
1966, págs. $73-109$ 
autônomas. Isto mesmo demonstra que não se pode sempre traçar uma linha entre a autonomia e certo tipo de Govêrno de Estado, descentralizado de modo diferente. Apesar de tudo isso, o conceito da autonomia pode ser bem usado no artigo seguinte enquanto descreve a organização da administração universitária.

Desejo enfatizar particularmente a derivação da autonomia como definida acima. Autonomia significa administrar, o que, por outro lado, é a prerrogativa do Estado através do uso de uma forma especial de organização. Em conseqüiência, gerir a administração das chamadas Universidades «Particulares» não é originalmente "autonomia" com êste sentido derivado, mas é atividade praticada geralmente por corporações e pessoas privadas para dirigir seus próprios negócios. Um assunto completamente diferente é que, enquanto a dependência da universidade particular com relação ao Estado - especialmente sua dependência financeira - está aumentando grandemente, os mesmos aspectos que pertencem ao direito público e à organização administrativa podem tornar-se significativos quando são levados em conta para estabelecer o estado das atuais universidades estatais.

\section{B. FORMAS DE ORGANIZAÇÃO}

\section{UNIVERSITAS MAGISTRORUM ET STUDENTIUM}

Como um exemplo para o tipo assim chamado clássico, popodemos considerar uma universidade que, sendo organizada como corpo acadêmico, dirija seus próprios negócios através de órgãos estabelecidos por ela mesma, com completa independência, livre de direção e contrôle externos. O fato é que tais universidades, ou ao menos alguma digna de nota, não existem mais. Dentre proeminentes universidades, as que mais se aproximam dêste tipo são, entre outras, as de Oxford, Cambridge e Dublin. Não há representação externa em seus órgãos administrativos (exceto a de caráter meramente honorário).

Mas, mesmo a posição destas Universidades não é tal que o Govêrno do país se torne incapaz de influenciar em seus negócios. Suas atividades, do mesmo modo que as de outras Universidades nas Ilhas Britânicas, têm sido levadas em nossos dias a um considerável grau com o auxílio de contribuições financeiras do Estado. É claro que esta dependência financeira abre caminho ao Estado, senão para um contrôle direto, detalhado, pelo menos para uma guia parcial, indireta. 
A UNIVERSIDADE COMO UMA POSIÇÃO FIXA NA MÁQUINA ADMINISTRATIVA DO ESTADO

Como o extremo oposto de uma universidade plenamente autônoma, podemos considerar uma universidade que tem sido absorvida como uma seção da máquina administrativa do Estado, que não tem autonomia de nenhum modo, ou que não tem fôrça para administrar seus próprios negócios através de seus próprios órgãos em bases essencialmente mais amplas do que as possuídas geralmente pelas autoridades mais baixas na administração do do Estado.

Um sistema como êste prevalece em países onde a estrutura social é baseada em ideologia comunista. Mas não apenas nestes Estados. Em muitos países que pertencem à esfera da ideologia política democrática, prevalece um sistema centralizado, conduzido pelo govêrno, de "universidades de govêrno", em um grau de maior ou menor estreiteza. É necessário fazer notar, de passagem, que, mesmo neste estágio, a classificação das formas de organização das universidades é considerada apenas para dar uma visão geral da matéria em discussão. Na prática, há um número. enorme de variações e combinações de tipos diferentes de universidades. As diferenças não aparecem apenas quando comparamos a administração universitária em diferentes países. Dentro do mesmo Estado, podem freqüentemente ser encontradas formas de organização que pertençam a diferentes categorias ou que combinem características de diferentes tipos em modos variados.

É interessante observar que, mesmo num país culturalmente antigo e forte como a França, prevalece um sistema de universidade estatal que é baseado na centralização administrativa estrita.

Isto é ainda mais digno de nota porque en seu tempo a Universidade de Paris foi uma dos protótipos de corporação universitária autônoma e livre.

A grande revolução na França fêz desaparecer todo o antigo sistema universitário, e não foi feita tentativa para reconstruí-lo nas mesmas bases. Pelo contrário, foi desenvolvido um sistema em que as "faculdades" em separado (sem estar incorporadas em universidades) tornam-se partes de um sistema escolar público, tendo apenas o ensino e a educação como seu trabalho.

A pesquisa científica era destinada a ser concentrada em algum outro lugar, ao mesmo tempo. Mais tarde o progresso levou a combinar as faculdades para formar universidade, que, agora, ao mesmo tempo em que são instituições de ensino, são também centro de pesquisa cientifica. Mas a centralização admi- 
nistrativa estrita permaneceu como modêlo básico para a organização. O país foi dividido em 19 departamentos administrativos de educação ("académies") e a capital de cada departamento é a sede de uma universidade. $\bigcirc$ Chefe da Academia, que ao mesmo tempo é o Reitor da Universidade, é um funcionário civil indicado pelo Presidente da República. Não sòmente êle é o administrador da Universidade, mas todo o sistema escolar do distrito está sob sua administração. Os podêres administrativos do departamento de professôres da universidade são muito limitados e o manejo das matérias está centralizado nas equipes. Há também equipes universitárias de articulação nacional, mas estas são de natureza puramente consultiva. Entretanto, é um grande êrro - diz um experiente homem de universidade francês - pensar que as universidades francesas crêem que estão sob pressão tirânica. A boa vontade do govêrno e a estima geral de que gozam as universidades, a tradição do liberalismo arraigado no espírito e costumes da França, e a solidariedade entre governantes e governados, ambos empenhados na prosperidade comum, resultam na fôrça das equipes universitárias, que carecem de autoridade independente, sendo esta considerável na prática. Suas sugestões são geralmente julgadas favoràvelmente. Üm conflito mais amargo é raro.

\section{ADMINISTRAÇÃO SEPARADA NÃO-ACADÊMICA}

A maior parte das universidades na América do Norte são "privadas." Entretanto, há também universidades fundadas ou mantidas por estados separadamente.

A organização da administração nas universidades americanas pertencentes a ambos os grupos (universidades privadas e universidades estatais) é geralmente a mesma: o corpo administrativo mais elevado é a equipe (curadores, coordenadores) composta de "leigos" (em vez de membros do quadro de professôres). Freqüentemente, mas não sempre, o "President" da universidade (cujas obrigações correspondem às de Reitor na Europa Continetal) pertence àquele quadro como membro. Também membro do quadro administrativo nas universidades sustentadas pelo Estado são considerados como curadores não sòmente do Estado mas também da universidade, mesmo quando são indicados pela autoridade do Estado. Nas universidades estatais, também, - não sòmente nas privadas - as associações de alunos tomam parte na seleção do quadro administrativo.

Nas universidades americanas, os quadros compostos de membros do corpo de professôres teòricamente participam na administração apenas em seus estágios preparatórios e na faculdade 
consultiva. Dêste modo êles comumente não podem exercer uma influência decisiva nos assuntos de nomeação, por exemplo, incluindo a eleição do "President." Mas na realidade êstes quadros podem, com freqüência, ganhar considerável autoridade.

Uma espécie de forma intermediária entre o sistema americano e o sistema plenamente autônomo antes descrito, com relação à composição do órgão administrativo mais alto é mostrado pelo sistema usado nas universidades britânicas (com exceção das mencionadas antes). Raramente representantes do govêrno do Estado pertencem ao quadro (Conselho, Câmara), que é o órgão administrativo mais alto, apesar do fato de que o Estado é financeiramente o principal sustentáculo da universidade.

O Quadro administrativo é comumente formado pelo ViceChanceler (correspondente ao Reitor), membros escolhidos peios professôres de dentre seu número, e (a maioria) membros escolhidos dentre pessoas não pertencentes à universidade; estas podem ser pessoas escolhidas dentre a esfera das profissões liberais, o mundo dos negócios, e o sistema escolar.

Variadas formas de administração separada não-acadêmica alastraram-se em várias direções fora da América do Norte e da Inglaterra, não sòmente nos países da Comunidade Britânica, mas também em outros. Por exemplo, na Suiça e na Holanda a autoridade estatal designa a maioria dos membros do quadro administrativo da universidade.

Quando se alcançou o ponto em que o Estado designa todos os membros do quadro administrativo, cometeu-se um desvio essencial do exemplo original, e chegamos mais perto de uma forma de administração universitária que é absorvida como uma parte da máquina administrativa do Estado. Isto é especialmente assim se o dever do membro do quadro é especificamente entendido como sendo o protetor dos interêsses do Estado, ou se os funcionários civis são designados regularmente como membros dêle. Mas a forma da administração separada é mantida mesmo em tal caso, e isto enfatiza a posição especial da universidade com relação ao govêrno do Estado, ao mesmo tempo que a comunicação entre - Estado e a universidade torna-se mais flexivel.

\section{FACULDADES CONFESSIONAIS}

As igrejas e seitas religiosas, especialmente a Igreja Católica Romana, têm universidades pertencentes a elas mesmas, em muitos países. Como estas universidades são especialmente destinadas a 
estar debaixo da direção da igreja particular em questão, não há muito em suas formas de organização administrativas que seja de interêsse para o estudo da autonomia universitária. Por isso farei menção delas apenas de passagem.

\section{OBSERVAÇÕES SUPLEMENTARES SÔBRE A CLASSIFICAÇÃO}

Já se tornou claro pelas observações prévias que as classificasôes - 1) plena autonomia universitária; 2) a universidade como uma parte da máquina administrativa do Estado; 3) administração separada não-acadêmica, não dão de modo algum um quadro completo e exaustivo das variadas formas de organização de si tuação administrativa das universidades. Nem tôdas as universidades podem ser classificadas desta forma. Na prática, as características dos tipos diferentes são combinados de modos grandemente variados, e pode ser acrescentado um material que é inteiramente estranho às características fundamentais dos tipos diferentes. Não podemos esperar mais das classificações do que aquilo que elas querem ser: apresentações muito esquematizadas dos aspectos mais importantes da organização prática.

Contudo, um outro aspecto que precisa ser enfatizado aqui é que a descrição de característica "técnica" da organização não dá sempre a imagem correta de como as decisões administrativas sáo tomadas atualmente. A prática estabelecida pode ser tal que um órgão mais elevado com fôrça de tomar decisões regularmente siga as sugestões feitas por outro inferior. Esta é a razão pela qual os quadros administrativos da universidade dos tipos 1) e 2) podem também ter fôrça atual muito maior do que se possa presumir da inspeção do diagrama administrativo.

Por outro lado, precisa-se ter em conta uma muito importante fôrça contrária à autonomia, que muitas vêzes não pode ser vista simplesmente pelo exame da estrutura organizativa, de nenhum modo. Eu quero falar do fato de que aquêle que financia a universidade, quer seja o Estado ou outra qualquer corporação. pode - sem levar em consideração a rêde administrativa - ganhar uma autoridade muito grande nos assuntos administrativos.

Especialmente naquilo que se refere à administração separada, não universitária, a gente ouve freqüentemente, entre professôres de universidade particular, dúvidas quanto a se um sistema administrativo de tal natureza possa ser considerado de algum modo como pertencente à esfera da autonomia universitária. Deve-se admitir que há razão para duvidar, por exemplo, nos casos em que ofundamento financeiro permanente de uma universidade é a 
municipalidade, que através de um corpo administrativo escolhido por ela mesma começa a dar normas em assunto que, - como será apresentado adiante mais detalhadamente - deveriam permanecer questões administradas autônomamente. Neste caso a questão da autonomia torna-se a da relação entre a municipalilade e a universidade, e isto não se aplica - como é o caso comum - à relação entre o Estado e a universidade. Na maior parte das vêzes, entretanto, a administração separada não-universitária pode ser comparada com um sistema plenamente autônomo pela razão de que, em ambos, as relações com o Estado adquirem um significado central. Por esta razão, e como interessa para a finalidade de minha tarefa dar uma delimitação ao conceito de autonomia, eu, de minha parte, não quero negar à administração separada não-universitária os caracteres de autonomia universitária, presumindo sempre que, na prática, o órgão administrativo externo não se torna sòmente o órgão do govêrno do Estado, mas funciona principalmente como o representante da universidade em suas relações com o govêrno.

\section{TENTATIVAS PARA A CENTRALIZAÇÃO DENTRO DE IIMITES NACIONAIS}

A expansão do ensino universitário, sua crescente versatilidade, e a necessidade geralmente admitida para seu ulterior desenvolvimento, tem levantado em muitos países a questão de se a centralização administrativa em escala nacional, adaptada ao caráter especial de instituições de aprendizagem mais elevada, é necessária para assegurar as condições melhores possiveis para o funcionamento próspero das universidades. Mas apenas em poucos países isto tem ido mais longe do que fazer planos e fundar comissões com finalidade de comunicação e consulta. Nas páginas seguintes, farei um breve aceno de dois sistemas particularmente dignos de nota, já bem estabelecidos.

O Comitê de Subvenção da Universidade Britânica é amplamente conhecido. De seu pais natal, êste sistema expandiu-se a alguns Estados recentemente independentes da Āfrica e Ásia, além dos países do velho Império Britânico. Em vários paises os membros do Comitê incluem comumente, além de leigos, alguns prodente é uma ocupação de periodo integral; freqüientemente, êle é o principal professor ou administrador da universidade e tem alguns secretários como assistente em regime de tempo integral. Em sentido juridico, o comitê não exerce autoridade administrativa atual: "de jure" é apenas consultivo. Essencialmente, sua autoridade e finalidade são baseadas no fato de que êle goza, por um 
lado, da confiança do ministro, e por outro lado, a estima dos universitários. Naturalmente, mesmo neste estágio, o comitê tem de pesar diferentes necessidades relacionando as uma com as outras e escolher os pedidos feitos pelas universidades. É na base dêste trabalho preparatório que o órgão respectivo do Estado decide (comumente no Parlamento como uma matéria burocrática), sôbre a soma total de subvenção a ser posta à disposição das universidades dentro de certo periodo. Agora vem um outro ponto importante no sistema britânico: o Comitê faz suas recomendações sôbre a divisão das subvenções entre as várias universidades. Como regra geral, o Ministro aceita as sugestões sem alteração.

Em suas relações com a universidade, o Comitê conserva também seu caráter consultivo (exceto quando o Ministro tenha delegado, através de medida especial, uma autoridade administrativa para isto). Além disso, as doações feitas a cada universidade são subvenções bloqueadas, cujo uso não tem sido especificado. Em princípio a universidade mesma as usa livremente, tendo a palavra final sôbre a ordem em que as várias necessidades devem ser satisfeitas. Mas, na prática, a universidade presta muita atenção às opiniões do Comitê de Subvenção sôbre o uso da subvenção bloqueada. Além dessas obrigações básicas, ao Comitê de Subvenções para Universidades parece, em alguns países, terem sido dadas outras incumbências, como também parece tornar -se, entre outras coisas, o órgão central do programa de ação da universidade.

$\mathrm{Na}$ Suécia, sete universidades e instituições de ensino superior têm um Chanceler desde 1954. Agora, depois da reforma realizada uns poucos anos atrás, tôdas as universidades e instituições de educação superior são supervisionadas por um departamento central dirigido pelo Chanceler da Universidade. O Rei nomeia - Chanceler com a indicação do Govêrno. A centralização que tem havido não é destinada a reduzir os direitos autônomos que as instituições de ensino superior têm tido desde tempos antigos. A finalidade especial da reforma tem sido incrementar a eficiência do planejamento dentro da estrutura nacional.

\section{II - POR QUE AUTONOMIA PARA AS UNIVERSIDADES?}

PONTOS-DE-VISTA GERAIS SÔBRE A TEORIA DA ADMINISTRAÇÃO

Um estudo da situação presente mostra que os sistemas administrativos em que a universidade não é uma parte fixa da máquina 
administrativa do Estado, mas goza de uma maior ou menor porção de poder para administrar seus próprios negócios, através de seus próprios órgãos, são - senão inteiramente predominantes - pelo menos muito espalhados pelo mundo. Qual é a razão para isso? Não pode ser mero acaso. Precisa haver algumas razões válidas e racionais.

Eu pretendo aqui deixar de lado a possibilidade de que a universidade possa funcionar sem ajuda do Estado para sustento econômico. Na prática, vêem-se mesmo "as universidades particulares" em geral procurando tal apoio econômico, em tôda parte. A opinião geral em nossos dias é que as universidades são de responsabilidade das autoridades públicas. Portanto, a organização da administração universitária é um problema de administração pública. Por que o princípio do contrôle centralizado não é geralmente aplicado à administração universitária dentro da estrutura nacional? Por que é usada a autonomia?

O objetivo de todo planejamento da organização administrativa deve ser tornar a máquina administrativa tal que sejam criadas as condições melhores possiveis para uma administração eficiente. Em outras palavras: com a despesa menor possível, ajustando-se rápida, segura e flexivelmente às condições que se mudam, a administração deveria procurar resultados, cuja obtenção tem sido conseguida através de decisões feitas ùltimamente pelos órgãos políticos do Estado como finalidade e projeto da atividade pública. A melhor máquina administrativa é aquela que, debaixo dêstes aspectos, obtém resultados de grau mais elevado.

Muitos sistemas de organização são empregados quando se procura uma instalação de uma boa máquina administrativa dentro de uma estrutura estatal. Aqui será necessário lidar apenas com o equilibrio dos princípios da centralização e descentralização.

Centralização é aqui entendida como a organização da administração de tal modo que seja dirigida a partir de um ponto central. No sistema baseado no principio da centralização, a administração é feita através daqueles órgãos cuja esfera de ação inclui a área inteira do Estado, ou que, se sua esfera de atividade é restrita seja na extensão como no assunto, são firmemente ligados ao órgão do govêrno central de tal modo que possa, seja por decretos gerais ou causas particulares, dirigir e orientar o funcionamento dêstes órgãos inferiores.

Descentralização, repetimos, significa delegação de incumbências administrativas a autoridades inferiores (ou corporações, ou 
outros organismos que exercem tarefas administrativas), às quais é dado seu próprio campo de autoridade e fôrça independente bastante grande para tomar decisões.

Comumente, quando nós falamos sôbre descentralização, pensamos a respeito de descentralização regional, cuja forma mais importante, usada em muitos países, é a autonomia municipal. Mas quando por centralização nós entendemos concentração de fôrça administrativa em um lugar de centralização, a centralização atual precisa ser considerada como uma organização de administração em que as autoridades especiais, que gozam de fôrça independente extensa, são criadas para obrigações especificas adnistrativas (em bases não regionais). Como, por razões práticas, é impossivel realizar a centralização de autoridades num Estado que não fôr inteiramente insignificante no tamanho, e desde que, além disso, levar adiante a descentralização até suas últimas conclusões significaria a dissolução do Estado, é neces sário aplicar êstes princípios lado a lado na organização, pràticamente, de todos os Estados. A questão de adaptar êstes dois principios opostos é uma das questões básicas na organização da administração. No conjunto, nenhum pode ser favorecido de preferência ao outro. Fortemente centralizada, a organização administrativa pode demonstrar a obtenção de melhóres resultados em algumas situações, enquanto em outras circunstâncias e áreas de administração a descentralização pode ser preferivel.

A autonomia universitária é administração descentralizada. Assim, a questão é a seguinte: quais são as razões - olhando para o assunto desde o ângulo do Estado como um todo - que tornam a autonomia apropriada para garantir os direitos autônomos das universidades? Ao perguntarmos isso, não partimos do fato de que as universidades tenham de modo absoluto um direito de autonomia que não precisa de explicação, de certo modo intrinseco, mas do fato de que a questão da organização da administração universitária é apenas uma parte da grande complexidade de problemas que a organização inteira da máquina administrativa do Estado cria, e que também precisa ser resolvida à base da consideração do que será mais apropriado para benefício comum. Tornando mais clara esta premissa, também se explica porque a administração universitária em países diversos tem sido organizada de modos essencialmente diferentes. Em alguns países o uso da administração centralizada, em outros o baseado em um sistema fortemente descentralizado, são tidos como os de melhores resultados. 


\section{RAZÕES PARA A AUTONOMIA UNIVERSITÁRIA}

Pelo material colecionado para a Conferência de Tóquio e nas discussões realizadas lá, conclui-se que, em quase todos os países, grande parte das universidades e, em grande parte dos paises, tôdas as universidades dependem, em maior ou menor grau, de ajuda financeira constante do Éstado. Este artigo como foi mencionado antes - destina-se a tratar destas universidades, total ou parcialmente subsidiadas pelo Estado.

A opinião pública é geralmente unânime em concordar que a universidade não pode ser isenta da supervisão do Estado e, por isso, não pode gozar da autonomia levada até suas últimas conseqüências.

Mas, em geral, o conceito nos países ocidentais - e não apenas dentro das universidades, mas também entre essas com relação à autoridade política - é que a universidade pode cumprit melhor stus tarefas se se thes garantir uma autonomia de limite muito amplo para administrar seus próprios interêsses.

$\mathrm{Na}$ justificação desta opinião, pode ser feita uma especial referência à grande expansão do sistema autônomo, que pode ser considerado como uma prova de que a experiência tem mostrado - bom resultado do sistema na administração de instituições de pesquisa científica simultânea e de instrução de alto nivel. Nós sabemos, na verdade, que nos nossos dias, a pesquisa científica, especialmente na parte das assim chamadas ciências "aplicadas", é praticada em larga escala fora das universidades. Mas, como centros de ciência teórica "pura", as universidades ainda têm predomínio. Sòmente nelas a pesquisa e o ensino, de várias formas e em larga dimensão, estimulam-se e sustetam-se mùtuamente, fazendo progresso e produzindo os melhores resultados em condições de trabalho livres de supervisão detalhada do govêrno.

Como na pesquisa científica em particular, pode-se fazer uma comparação com o trabalho criativo de um artista. Quando a tarefa - quer pertença à esfera das ciências ou à das artes requerer visão independente e pensamento criador, então um escopo mental suficiente é pelo menos desejável, se não indispensávè condição para sua realização vitoriosa. Um artista pode também receber uma encomenda de valor: pintura de um retrato, escultura de uma estátua, composição de um hino. Mas, não ocorreria a ninguém supervisionar detalhadamente a execução do artista neste trabalho. O artista precisa estar livre para escolher seu próprio caminho. E a mesma coisa se aplica a um professor cientista ou universitário, não apenas no trabalho de pesquisa mas também 
no ensino e educação. É necessário frisar o fato de que o escopo da instrução universitária não se limita à transmissão de conhecimento do professor ao estudante. $O$ aspecto de informação contrói apenas a base vital, com a qual se combina o ensino em determinado tipo de pensamento necessário para resolver pro blemas novos. Com relação à maioria dos estudantes, nós podemos contentar-nos com metas bastante modestas. Mas há sempre entre a juventude da universidade aquêles dos quais a sociedade precisa depender na sua esperança para aplicação do conhecimento e o nascimento de nôvo conhecimento. Um professor universitário precisa descobrir estas pessoas capazes, que irão continuar seu trabalho.

Êle precisa apoiá-las e encorajá-las. Precisa dirigi-las de tal modo que sejam capazes, por sua própria parte (talvez ainda muito modesta), de contribuir para ulterior construção do grande edifício da ciência. Como esta espécie de direção pode ser dada por um professor cientista, os pontos-de-vista acima tornam-se argumentos não só em favor da demanda da liberdade intelectual de cátedra, mas também da preservação da universidade como uma instituição que funde ensino com pesquisa.

As organizações administrativas que podem ser usadas para garantir a liberdade intelectual dentro da universidade serão dis cutidas mais adiante com maiores detalhes. Enquanto me refiro a isso, quero aqui enfatizar a importância particular que as questões das nomeações universitárias e do direito de permanecer no cargo têm a êste respeito. Pela harmonização do tratamento e decisão sôbre estas questões em base autônoma, são criadas bases favoráveis para prover as universidades com a melhor equipe possivel para pesquisa e ensino.

\section{CONTRA-ARGUMENTOS}

Há sempre o perigo, quando se descentraliza a administração, de que os interêsses nacionais como um todo não recebam uma consideração suficiente, porque as unidades administrativas descentralizadas olham a matéria desde seu estreito ponto-de-vista. Este perigo está presente na autonomia universitária também.

Pensamos, por exemplo, em descobrir a carência de médicos para o país. Isto é assunto nacional, que requer intervenção do Govêrno se não puder ser encontrado outro método.

É também concebivel que as universidades possam retirar-se para dentro da forma de sua autonomia, e tornam-se divorciadas 
da sociedade ao redor delas. Neste caso elas desviam-se para direção errada. As finalidades pelas quais lhes foi garantido o direito de autonomia não seriam conservadas por mais tempo.

\section{A RESPONSABILIDADE DA UNIVERSIDADE}

Os pontos mencionados acima são razões para dar grande ênfase à responsabilidade ligada à autonomia universiária.

A autonomia universitária não pode ser baseada em nenhum privilégio, mas apenas na consideração, extraída de uma longa experiência, de que esta espécie de sistema administrativo aumenta essencialmente as possibilidades para que as universidades cumpram bem suas tarefas.

A autonomia não é destinada a isentar a universidade da dependência da crítica pública. Não pode separá-la da comunidade nacional. A universidade precisa estar profundamente côns cia de sua responsabilidade como serva da sociedade. Não pode fechar-se dentro da tôrre de marfim de sua autonomia. A autonomia não existe meramente para a universidade, mas a universidade para a sociedade, e sua autonomia é necessária somente para levar adiante suas tarefas de serviço social mais competentemente.

\section{III - OS ELEMENTOS CONSTITUTIVOS DA AUTONOMIA}

\section{A. LINHAS GERAIS}

Já tem sido mencionado nas páginas precedentes que o conceito da autonomia universitária continua muito obscuro. Mesm.) nesta situação não é minha intenção empenhar-me em dar uma definição acurada e perfeita do conceito. De fato, apenas tenciono dar uma relação do que foi apresentado como essencial para a ferência de universitária na troca de pensamento e idéias da Con. ferência de Tóquio, e acrescentar uma parte de minhas próprias
observações.

Voltando às questões sôbre as formas de organização que já foram discutidas, eu gostaria de, em primeiro lugar, afirmar que parece não existir mais o fundamento geral para a idéia de que só a forma de administração conhecida por quadros "universitários" dentro da universidade é atual para a autonomia universitá- 
A administração separada não-universitária é também conhecida como autonomia; nos Estados Unidos especialmente, esta é considerada como uma forma de administração melhor do que a autonomia universitária. Não há razão para pesquisar mais profundamente esta avaliação da superioridade, nem para estudar em profundidade as espécies de casos em que o sistema de administração separada não-universitária possa levar a uma situação de tal dependência que possa minar a autonomia universitária. Como, na prática, o relacionamento entre a universidade e o Estado quase sempre se torna a questão mais importante, concentrar-me-ei nêle. Considerando especialmente a relação entre o Govêrno e a universidade, ocuparei as páginas seguintes em explicar que espécies de fôrças administrativas são consideradas típicas para a autonomia pelos círculos universitários em nossos dias.

\section{A RESOLUÇÃO DA CONFERÊNCIA DE TÓQUIO}

Parece conveniente começar pelo fim, e por isso incluirei em primeiro lugar aqui a tôda a resolução proferida na Conferência de Tóquio. Seu principal conteúdo consiste em "cinco pontos" prèviamente preparados, que foram apresentados para ser estudados pela conferência.

"É dever das universidades contribuir para o mais alto desenvolvimento tanto da comunidade nacional à qual elas pertencem, como da causa da ciência internacional. A experiência torna evidente, entretanto, que elas satisfazem estas funções mais eficazmente quando gozam de um grau mais alto de autonomia e estão em posição de manter padrões acadêmicos por terem uma voz decisiva com relação aos seguintes assuntos:

1. Quaisquer que sejam as formalidades para a nomeação, a universidade deveria ter o direito de escolher seu próprio quadro de professôres.

2. A universidade deveria ser responsável pela seleção de seus estudantes.

3. As universidades deveriam ser responsáveis pela formulação dos currículos para cada grau e para o estabelecimento dos padrões acadêmicos. Nos países em que os graus, ou licença para praticar a profissão são regulados por lei, as universidades deveriam participar efetivamente na formulasão dos currículos e na fixação dos padrões acadêmicos. 
4. Cada universidade deveria dar as decisões finais igualmente para o programa de pesquisa realizado dentro de suas paredes.

5. A universidade deveria ser responsável, dentro de amplos limites, para a distribuição entre as suas variadas atividades dos recursos financeiros disponiveis, ou seja espaço e equipamento, fundos financeiros; rendas periódicas de operação.

Entende-se que, embora esta liberdade seja necessária para o adequado cumprimento da função da universidade, tal autonomia requer um senso de responsabilidade da parte de todos aquêles que compõem a universidade seja como administradores, professôres ou estudantes."

Quero frisar também que os "cinco pontos" da resolução foram elaborados especialmente com o sistema britânico-americano de universidades em mente, embora dentro daquele sistema cultural existam também universidades que não preenchem os requisitos. Por outro lado, há numerosas universidades alhures, que realizam plenamente êstes critérios de autonomia. Mas no momento presente há muitas universidades no mundo para as quais c cumprimento dêsses requisitos é um desejo irrealizado em graus

É minha intenção mais tarde, ao mesmo tempo em que eu der minha própria opinião sôbre os elementos componentes da autonomia universitária, discutir um pouco mais detalhadamente os vários pontos da resolução de Tóquio - alguns mais do que outros. Antes de principiar esta análise, farei, entretanto, um

\section{A DISCUSSÃO DE TÓQUIO} O tema "A Autonomia Universitária", seu Sentido Hoje"
foi cuidadosamente considerado prioritário na discussão da sessão plenária da conferência. Como consequiência, a discussão foi menos dirigida para o princípio da autonomia como tal princípio que parece ser geralmente aceito - do que para um número de outros itens básicos tratados sob muitos aspectos nos assuntos em
pauta da conferência.

As linhas diretrizes traçadas para a discussão pelo presidente da Associação em sua exposição introdutória e nas conferências preliminares resultaram em especial atenção para com os proble- 
mas correntes. Entretanto, muitos oradores freqüentemente voltaram às asserções gerais feitas nos temas de introdução - por exemplo, que na sociedade moderna a relação da universidade com o Estado torna-se a questão central de autonomia: que a autonomia é apenas relativa e não absoluta; que a noção de autonomia deve ser esclarecida, atendida, e sempre reavaliada separadamente dentro da estrutura de cada sociedade, levando em consideração a situação que muda constantemente; e que o real valor e garantia da estabilidade na autonomia universitária deve ser encontrada, não tanto nas afirmações escritas ou nas organizações administrativas, mas na opinião pública convencida de que quanto mais liberdade é dada à universidade sob certos aspectos para tomar suas próprias decisões, mais eficientemente ela pode servir à comunidade. Igualmente, em grande número de ocasiões os oradores acentuaram a responsabilidade da autonomia universitária (como também de seu quadro de professôres e corpo estudantil, ambos considerados como um todo e como pessoas individuais) para com a comunidade.

Muitos oradores acentuaram fortemente a importância dos "cinco pontos" que foram apresentados como base para a discussão.

A discussão iluminou práticas que, em vários países, diferem dos pontos mencionados antes, debaixo de alguns aspectos, e foram feitas sugestões para algumas trocas e melhoramentos.

Tendo em mente as reservas que tinham sido expressas, nos temas de introdução, sôbre os "cinco pontos", pode-se considerar que a discussão mostrou que, a despeito das diferenças no "background" cultural, entre os dados e entre as universidades, a conferência estava preparada para aceitar os "cinco pontos."

A discussão como um todo, tanto dentro como fora da estrutura dos "cinco ponos", trouxe muitos interessantes pontos-devista sôbre a vida universitária em diferentes partes do mundo. Uma menção especial foi feita a respeito dos problemas administrativos causados pelo crescimento das universidades e nas soluções práticas aplicadas em diferentes países. Ficou patente pela discussão, e ficou claro num tema, que o propósito essencial da conferência era, como tinha sido antecipado, ficar mais na troca de opiniões e experiências do que na tomada de decisões formais.

Juntamente com "os cinco pontos", entre as questões part1culares relacionadas, algumas mais do que as outras, com a "autonomia universitária", muita atenção foi prestada à participação dos estudantes na administração da universidade. Pareceu ser geralmente aceito que o "autogoverno" dos estudantes como descrito 
no programa de estudos (serviço social dentro do corpo de estudantes e consulta nos assuntos de estudos), (pode ser útil e apropriado.

Entretanto, opiniões diversas e bastante contrárias foram expressas com respeito à sabedoria de ir mais longe pela outorga aos grêmios estudantis de um papel na administração geral da universidade. Alguns oradores chamaram isto de progresso. Outros se opuseram a isto fortemente, mostrando que os postos tomados nos assuntos administrativos eram freqüentemente relacionados com as ambições dos estudantes e, dêste modo, tornavam mais difícil a condução flexivel da administração. Em todo caso, a discussão indicava que a questão da participação estudantil na administração universitária precisa de cuidadoso estudo antes que um substancial aumento da tal "administração estudantil" possa ser encarado.

Muitos dos oradores se detiveram a respeito da cooperação entre as universidades. Esta é também uma matéria que precisa de contínuo estudo. Naquilo que se refere à autonomia universitária, o principal ponto frisado foi o de que quanto mais as universidades forem capazes de encontrar as necessidades da comunidade através da cooperação mútua, tanto menos suas atividades precisarão ser dirigidas através de influências externas.

Finalmente, como $u \mathrm{~m}$ dos mais importantes assuntos discutidos, considerarei a relação entre o Govêrno e a universidade.

Esta matéria foi levantada em grande número de ocasiões, particularmente com relação às finanças da universidade. Foi dito que a dependência financeira da universidade para com o Govêrno poderia pôr em perigo sua autonomia. Mencionou-se também a possibilidade de proteger a autonomia universitária pela legislaçâo procurando, por exemplo, que não se pudesse fazer corte de ano para ano no orçamento da universidade sem o consentimento da própria universidade, ou que uma percentagem (fixa por lei) da renda bruta nacional no orçamento estatal fôsse colocada à dis posição das instituições da pesquisa científica e do ensino superior.

Por outro lado, foram feitas objeções contra tais normas legais, e foi acentuado que a tarefa mais importante era construirùma relação de mútua confiança entre o Govêrno e as universidades.

A opinião pública e política deveriam estar convencidas de que a garantia da autonomia universitária é um assunto de inte-
rêsse nacional. 
Estes tópicos acima mencionados da discussão conduzem às seguintes considerações:

A autonomia universitária diz respeito a cada universidade individualmente, como uma medida administrativa separada. Mas na sociedade moderna - enquanto conserva as vantagens da autonomia - o progresso da cooperação entre as universidades torna-se inevitável. Para servir a comunidade tanto quanto possivel, as universidades deveriam planejar programas coordenados entre si mesmas.

A autonomia está intimamente ligada com o assunto das relações entre o Estado e as instituições de nivel superior como um todo, isto é, tôdas as universidades e instituições de ensino superior juntas dentro da estrutura nacional. Um planejamento centralizado, cuidadoso, e contínuo é requerido para uma politica nacional nas instituições de ensino superior como tal, isto é, para o planejamento da educação e instrução de nivel universitário, a criação de circunstâncias favoráveis para a pesquisa científica levada adiante nas universidades, a criação de novas universidades mantidas ou subvencionadas pelo Estado, e em geral para a designação de fundos públicos para satisfazer as necessidades mais importantes e urgentes. É de extrema importância descobrir e desenvolver, pela comparação das experiências de diferentes paises, as formas de organização administrativas que poderiam, neste contexto, servir melhor os interêsses públicos.

\section{ASSUNTO DE NOMEAÇÃO}

É minha opinião que, naquilo que diz respeito à autonomia universitária, uma das matérias mais importantes é o primeiro ponto de resolução de Tóquio: conservar a autoridade atual para indagar e selecionar nos assuntos de nomeação dentro da própria universidade, mesmo quando o ato formal de nomeação venha de fora da universidade. Isto é de importância especial para o quadro de professôres, isto é, daqueles que são destinados ao ensino e à pesquisa. Com respeito aos administradores, a matéria é de menos importância. Mas mesmo que a atual autoridade para a nomeação pertença a um corpo externo é necessário orientar o procedimento da nomeação de tal modo que a universidade possa considerá-los como seus funcionários, e não como representantes, dentro da universidade, de alguma autoridade estranha. Sem mais longas explicações, é claro que isto é um pré-requisito muito importante para o trabalho vitorioso dos administradores. 
É necessário proceder um tanto mais compreensivamente quanto à nomeação dos professôres e pesquisadores. Não me deixarei levar por uma detalhada discussão da questão de quanta importância deveria ser dada à habilidade de ensinar e quanto ao mérito científico, no julgamento da competência e da superioridade. Farei apenas notar que, pelo menos nas universidades européias, a ênfase principal é dada ao mérito científico para a nomeação dos possuidores dos cargos mais altos, isto é, dos cargos de professôres. Exatamente o contrário pode-se aplicar aos cargos inferiores, que são comumente preenchidos pela própria universidade, como se nêles a habilidade de ensinar e outros pontos de conveniência possam pesar mais.

$\mathrm{Na}$ minha opinião, o principal fundamento em que a realização da autonomia nos assuntos de nomeação pode estar baseado, é a segurança garantida da carreira de magistério que é exigida pelo interêsse público. Se as decisões da nomeação são tomadas do lado de fora da universidade, há o perigo de que outros aspectos que não os da habilidade no ensino e mérito científico possam influenciar nestas decisões. O sistema estabelecido, em que as decisões nos assuntos da nomeação estão centralizadas nos quadros de professôres, mesmo que freqüentemente se use o auxílio de peritos, será condenado. A segurança da carreira de magistério dêste modo torna-se incerta. Isso pode impedir professôres e pesquisadores jovens de seguir uma carreira universitária. Não apenas a universidade sofre, mas - como o desenvolvimento forte e o funcionamento efetivo da universidade serve ao interêsse público - o Estado e a Nação inteira sofrem, também.

Pelas razões acima em particular, deve-se tomar cuidado para que as nomeações para os cargos universitários não se tornem de caráter político. Como para certos cargos na máquina administrativa atual do Estado, pode ser agradável ao govêrno preenchêlos com pessoas que representem seus próprios pontos-de-vista políticos. Mas a tarefa da universidade é tão distinta e tão especifica que não há razão para estender o sistema de nomeações políticas à universidade. Tal sistema prejudicaria a universidade e o interêsse público, como se discutiu acima. É também necessário, com relação a isso, mencionar o direito dos professôres da universidade de permanecer no cargo. É claro que a luta para a maior objetividade possivel em avaliar o mérito profissional do professor, e a garantia da autonomia nas questões de nomeação, podem tornar-se sem sentido, se não se proteger o direito do professor universitário de permanecer no cargo. 


\section{ADMISSÃO DE ESTUDANTES À UNIVERSIDADE}

De meu lado, não estou inclinado a considerar como um atri buto fundamentalmente importante para a autoridade universitárıa a decisão sôbre o número e composição do seu corpo de estudantes e sua seleção. Neste aspecto a universidade não difere essencialmente das escolas em geral (não incluindo as escolas de educação obrigatória). De certo, muitas decisões derivam desta direção que a universidade exerce com absoluta independência. Mas isto é devido mais à natureza da própria matéria, e não ao fato de que ela seja da alçada da universidade. Na tradição européia, uma universidade deveria estar realmente aberta a todos aquêles que tenham alcançado um certo padrão, mas a carência de facilidade de ensino, isto é, acomodações e equipamento, ou corpo docente, pode impelir a universidade - exatamente como qualquer outro instituto de educação - a limitar o número de estudantes em certos campos de estudo. Para determinar o nivel que deva ser o padrão requerido para a admissão à universidade, a universidade precisa comumente levar em consideração o que pode ser dado pelas escolas do país. Como a própria universidade faz a seleção dos estudantes, isto não pode ser tomado como um critério particularmente apropriado de autonomia também.

Mesmo quando a autoridade da universidade de decidir a respeito da admissão dos estudantes seja considerada como sendo um direito autônomo, o dever da universidade para com a comunidade nacional precisa ser colocado como um contrapeso àquele direito. A discriminação não deve ser permitida. As portas da universidade não devem ser fechadas para o aspirante por nenhuma razão a não ser aquelas que dizem respeito à qualificação para um estudo vitorioso.

Não pretendo aqui ir mais longe na questão de quantos es tudantes devam ser aceitos anualmente na universidade e em cada ramo de estudo. Em cada universidade êste problema é resolvido na prática comumente conforme seus próprios recursos, isto é, suas acomodações e equipamento, tanto quanto como de acôrdo com o quadro de professôres. Mas num país com muitos institutos de educação superior esta questão, também, deve ser resolvida dentro da estrtura nacional, e as instituições do país de educação superior precisam ser modeladas de tal modo que possam admitir um número pré-requerido de estudantes. Dêste modo o assunto tornarse da alçada da política universitária, mas como um todo pertence à esfera da autonomia universitária .

O mesmo acontece com a "superprodução". Pode-se dizer, que se, por exemplo, profisisonais de atividade livre como ad- 
vogadus e médicos são produzidos em número demasiado grande, isto pode levar ao abaixamento da moral profissional. Mas impedir tais defeitos com antecedência não é tarefa que diz respeito à autonomia universitária .

\section{EXAMES, CURRÍCULOS, REQUISITOS PADRÕES}

Durante a fase mais antiga do desenvolvimento universitário, os exames foram, e em muitos países ainda são, uma norma estabelecida independentemente pelas universidades. Em nossos dias, o sistema que freqüentemente prevalece em conexão com a autonomia universitária nos exames é o de que, nas profissões que requerem ensino universitário (por exemplo na profissão de advogado), um diploma universitário apenas não é suficiente para assegurar competência formal. Uma prova de madureza, dada diante de algum organismo externo (seja estabelecido ou reconhecido pelo Govêrno) é exigida, como o "Bar Examination" nos Estados Unidos.

Em outro sistema muito difundido, um diploma universitário, por si mesmo, determina a competência para satisfazer os requisitos da profissão em questão. Mas neste caso o Estado comumente reserva-se o direito de decidir, geralmente através de medidas legislativas, a respeito dos requisitos para estas profissões. Eu não ve 10 nada incompativel com a autonomia universitária no último sistema também.

O estabelecimento da qualidade e dos principais tópicos dos exames não podem ser completamente separados da formulação dos currículos, que por seu lado devem ser considerados como competência das tarefas internas da universidade. É natural que o padrâo requerido nos exames e no desenvolvimento do estudo precisa continuar sendo da competência interna da universidade.

\section{PLANEJAMENTO DE PESQUISA PROGRAMADA}

Uma atenção mais detalhada será prestada mais tarde para mostrar como a pesquisa científica faz um papel essencial na vida universitária, e como é importante que a universidade e seus cientistas gozem de grande grau de liberdade, especialmente no seu trabalho de pesquisa. No momento, nossa atenção será focalizada só no aspecto administrativo desta matéria: o trabalho de pesquisa programada realizado dentro da universidade.

Nos países comunistas, é considerado natural que o govêrno do Estado coordene os planos mais importantes de pesquisa que devem ser abordados na universidade. No conceito ocidental, esta 
espécie de direção estranha é evitada, embora o trabalho de pes quisa possa ser levado adiante nas universidades como um tra balho "feito sob medida", em geral para satisfazer primeiramente às necessidades públicas. $\mathrm{O}$ planejamento da pesquisa programada, em tôda a sua extensão, é considerado como uma parte dos assuntos internos da universidade. Tem-se em grande importância que êste planejamento não deva restringir a liberdade de movimento dos pesquisadores.

\section{A LIBERDADE FINANCEIRA DA UNIVERSIDADE}

A fim de ser claro, repito aqui que êste artigo trata apenas das universidades que são parcialmente ou totalmente sustentadás pelos fundos do Govêrno. No seu conjunto, as questões levantadas também se aplicam às universidades sustentadas pelas municipalidades. São também parcialmente aplicáveis às universidades particulares. Mas êstes dois grupos mencionados por último podem ser preteridos aqui por causa de seu significado relativamente pequeno agora, que diminui sempre mais na prática.

Um Estado que financia o trabalho de uma universidade, naturalmente também quer supervisioná-lo e observá-lo. Observar o emprêgo dos fundos, no sentido de garantir as finalidades especificas para as quais foram dados, de certo modo não contém nada que possa prejudicar a autonomia universitária. Mas, impondo condições para o emprêgo dos fundos, o Estado pode influenciar muito profundamente na vida e projetos das universidades.

Pode isto pôr em perigo a autonomia universitária? Sim, certamente pode, embora o perigo não seja tão grande como pareça à primeira vista. A razão principal para isso é, em grande parte, que as garantias universitárias estão comumente incluidas na parte básica "fixa" do orçamento do Estado, que no minimo é feito por cima para as despesas correntes, e de maneira prévia, sem qualquer consideração ulterior. Sua redução é pràticamente inconcebivel. Podem ainda ser legalmente fixas, por exemplo no caso em que os professôres do Estado são funcionários civis em exercicio.

A inclusão de item de seu salário no orçamento do Estado não é mais uma matéria para ser considerada. Em tal caso, a sujeição para a consideração e, ligado com isso, a possibilidade de estabelecer condições, vem à tona prnicipalmente quando a universidade está planejando reformas caras ou ampliações. Não se segue da autonomia universitária que o provedor dos fundos não possa em casos como êstes ter uma influência decisiva para formular e realizar os planos. É do interêsse do Estado, que tem 
em vista interêsse público, que, enquanto as decisões estão sendo tomadas, os planos da universidade sejam tomados em considera ção cuidadosa.

Indubitàvelmente, quanto maior liberdade a universidade tiver no emprêgo de suas finanças, tanto mais flexivel poderá tornar-se seu funcionamento. Há certas lamentações, e com certa razão, entre muitas universidades estatais sôbre as dificuldades causadas pela dependência estrita e detalhada quanto ao orçamento.

Não há possibilidades suficientes para experiências de reforma, e a realização de reformas pode tomar anos. Isto se aplica especialmente ao aspecto do ensino. Como para a pesquisa científica, pode-se notar que em muitos países, vários sistemas têm sido elaborados para sustentar o trabalho de pesquisa, através dos quais os defeitos causados pela estrita dependência orçamentária têm sido diminuídos nas universidades, também.

O sistema de financiamento britânico-americano, em que a ajuda do Govêrno às universidades é dado em forma de verbas globais, é considerado como o de melhor funcionamento na prática. A universidade conserva sua autonomia. Em princípio, a universidade recebe apenas recomendações para sua administração de recursos por parte do organismo responsável pela concessão da ajuda estatal. Mas, na prática, ela raramente se desvia destas recomendações. Dêste modo, os interêsses da administração central e a autonomia universitária têm andado de comum acôrdo. O sistema britânico-americano como tal, contudo, não pode ser seguido por um sistema de universidades estatais em que o corpo de professôres universitários são funcionários civis em exercício. Mas a autonomia de tais universidades pode também tornar-se mais efetiva através da ampliação de seu campo de ação com relação a matérias que não sejam as verbas de salário. Entretanto, continua existindo a restrição de que esta espécie de liberdade no uso dos fundos não dá autoridade para fazer novas despesas fixadas além do periodo orçamentário, e de modo a suplantar a autoridade orçamentária do Estado.

\section{A RELAÇÃo ENTRE O GOVÊRNO DO ESTADO E A UNIVERSIDADE}

A observação da liberdade da universidade em suas finanças traz à tona com clareza particular um assunto que agora invade a questão inteira da autonomia universitária, especialmente a relação do govêrno do estado com a universidade.

A autonomia universitária não deveria ser entendida como um sistema em que, por um lado, os "direitos" do Estado, e por outro, os da universidade opor-se-iam uns aos outros. Há ainda 
menos razão para entender que a matéria deve ser de tal natureza que a universidade, invocando sua autonomia, defenda-se a si mesma contra os ataques e opressóes do Estado. O ponto-departida deveria ser inteiramente diferente: a universidade deveria ter autonomia somente no caso, e somente no limite em que isso seja benéfico para o interêsse público. Foram dadas razões acima que fundamentam a controvérsia de que a universidade possa servir a comunidade mais eficazmente e com melhores resultados se ela toma decisões com certo grau de autoridade independente, do que se ela fôr uma parte da máquina administrativa estritamente centralizada do Estado. Êste princípio básico pode ser aplicado apropriadamente ao uso dos recursos financeiros. Entretanto, deve-se lutar por um sistema flexível onde permaneça a fôrça supervisora do Estado.

Naturalmente é próprio dos órgãos do Estado decidir quanto dos fundos estatais deve ser destinado para as instituições de educação superior durante cada período orçamentário. A única competência da universidade autônoma é fazer sugestões e fazer pedidos. Na prática, a universidade com dificuldade consegue a soma total requerida por ela. A razão para o corte não é ne cessàriamente a de que o Govêrno não desejaria admitir que as reivindicações da universidade não sejam bem fundadas. Normalmente, o compromisso a respeito das reivindicações da universidade é causado simplesmente pela necessidade de conter o gasto do Estado a fim de equilibrar o orçamento. Quando as sugestões da universidade são cortadas dêste modo durante a redação e aprovação do orçamento do Estado, seria importante, do pontode-vista da autonomia, que a universidade pudesse contribuir efetivamente para a fixação das prioridades. Como na distribuição das verbas, na estrutura nacional, entre as diferentes universidades e institutos de ensino superior, seria necessário um órgão central com competência especial e autoridade para planejar e executar os estágios de preparação, refôrço e realização do orçamento do Estado. Voltarei a esta matéria mais adiante.

\section{LIBERDADE UNIVERSITÁRIA}

Quando se discute a autonomia unviersitária, é necessário dizer umas poucas palavras sôbre a "liberdade universitária." Antes de tudo direi que o significado dêste têrmo não é claro. Alguns querem dar-lhe um sentido mais amplo, outros, um mais estrito.

Algumas vêzes se the dá um sentido tão amplo que a autonomia universitária é considerada como derivação dela. Eu, pes- 
soalmente, uso-a num sentido bastante restrito, considerando a liberdade dos professôres universitários para ensinar e pesquisar seu principal atributo.

A liberdade em ensinar, naturalmente não significa que o professor universitário não tenha obrigação de ensinar assuntos e matérias que, de acôrdo com o currículo devidamente aprovado, são parte de seus deveres de ensinar. A liberdade no ensino precisa ser entendida como um elemento de liberdade na pesquisa.

O professor universitário precisa ter um direito protegido de fato no seu trabalho de ensinar para apresentar pensamentos $\epsilon$ opiniões - não interessando quanto possam ser impopulares, ou quão diferentes da opinião prevalente - que êle tenha descoberto na sua investigação cientifica. Deve-se-lhe permitir gozar de tal liberdade que êle possa ter a procura da verdade cientifica como sua única meta. Seu direito de permanecer no cargo precisa ter proteção legal suficientemente efetiva, que lhe garanta um estudo objetivo - preferivelmente dentro da própria universidade — das razões apresentadas em favor da demissão do cargo e previna interrupção arbitrária do serviço, como, por exemplo, a demissão baseada na política.

A mais séria ameaça à liberdade do professor universitário no ensino e na pesquisa dentro da moderna sociedade é o conflito com o regime político dominante. Todo o mundo universitário deve opor-se a esta ameaça enèrgicamente e com tôda a sua fôrça.

O professor universitário precisa ser protegido na sua liberdade de ensinar e pesquisar, mesmo quando expresse opiniões que não são agradáveis àqueles que têm autoridade politica. Entretanto, é necessário neste contexto dar grande ênfase à responsabilidade ligada ao direito de liberdade universitária. Quanto maior a autoridade pessoal que o professor universitário goza, maior razão há para considerá-lo um dos líderes intelectuais de seu povo.

É necessário ampliar luz e não agravar controvérsias. Deverse-ia além disso sublinhar que a liberdade universitária não deve ser usada para construir um muro de proteção para qualquer atividade de interêsse externo. No Estado onde os direitos do cidadão incluem atividade política livre, os professôres universitários têm naturalmente êste direito também. Mas, isto não significa de nenhum modo o uso da cátedra de professor como fôro político. Nem a liberdade universitária o livra da responsabilidade que os cidadãos têm em sua atividade política. $O$ último ponto aplica-se também aos estudantes. A filiação do corpo estudantil a uma 
universidade não dá uma posição privilegiada ou protegida, especialmente com relação à atividade política. Os estudantes têm o mesmo direito a uma atividade política como outros cidadãos do Estado, mas com igual responsabilidade.

\section{IV - A ADMINISTRAÇÃO DA UNIVERSIDADE COMO UMA PARTE DA ADMINISTRAÇAO DO ESTADO}

\section{A OUTORGA DE DIREITOS AUTÔNOMOS À UNIVERSIDADE SERVE AO INTERÊSSE PÚBI.ICO}

Pode-se encontrar em tôda a administração do Estado, entre os órgãos de campos diferentes de administração, a tendência de tentar obter para si mesmos tão grande autoridade no exercício quanto possivel. Isso, por seu lado, está em oposição ao desejo da administração central de unificar a direção e a centralização da fôrça de decisão. Em nenhum dos lados as tendências precisam estar baseadas em ambições pessoais apenas, mas numa intenção verdadeiramente sincera para uma realização satisfatória dos deveres administrativos ligados ao órgão em questão. Como já se mencionou, a organização da administração do Estado é uma harmonização contínua dos princípios da centralização e descentralização, que deve estar baseada na consideração de sua conveniência para o interêsse da comunidade nacional como um todo. A questão da autonomia universitária precisa ser igualmente olhada sob esta luz.

Depois de estudar os argumentos pró e contra a autonomia universitária, cheguei nas páginas precedentes à conclusão de que a concessão de certos direitos autônomos às universidade é de absoluta vantagem para o Estado. A universidade é uma serva da sociedade, $e$ isto precisa estar sempre na mente quando se dirige ao trabalho. A autonomia. essencialmente, faz aumentar para as universidades as chances de exercitar bem esta capacidade de serviço. É importante que o público e os que têm autoridade politica, estejam convencidos da necessidade da autonomia universitária para o completo benefício do Estado.

COMBINAR A NECESSIDADE DE CENTRALIZAÇÃO NACIONAI. COM O SISTEMA AUTÔNOMO

Em todos os Estados de alguma importância, a grande expansã̃o das universidades instituições de ensino superior levanta a questão de como a necessidade de uma centralização nacional - 
especialmente o plano geral e o uso mais apropriado dos fundos estatais - será realizada do ponto-de-vista da organização administrativa e de como, ao mesmo tempo, os beneficios resultantes da autonomia universitária serão protegidos na maior medida possivel. Em minha opinião, isto está se tornando uma questão de importância capital, que requererá muita atenção.

$\mathrm{Eu}$ dei informações a respeito das formas de organização empregadas em alguns países. Parece que no sistema francês de administração universitária fortemente centralizado, os órgãos de consulta que atuam dentro da estrutura nacional têm sido constituídos para assessorar os gabinetes. Neste artigo o Comitê de Subvenção da Universidade Britânica e o sistema sueco de Chanceler representam tais formas de organização que foram adaptadas ao sistema de autonomia universitária.

Partindo da controvérsia de que a autonomia universitária serve ao interêsse público, dever-se-iam fazer esforços para realizar a centralização sem reduzir essencialmente a autonomia. E de importância especial que a resolução dos assuntos referentes às nomeações para o cargo e o direito de permanecer no cargo deveria continuar a ser tomada por organismos que gozem da confiança dos círculos universitários, e que a proteção da liberdade no ensino e pesquisa não deveria ser infringida.

Parece que tudo isto pode ser realizado melhor se o organismo central se tornar um elo entre o govêrno e as universidades, como um elo que goze de confiança tanto do govêrno como das universidades. Podem ser criadas circunstâncias favoráveis ao nascimento de tal situação através de preparativos da organização administrativa, particularmente dando às universidades possibilidades de contribuir de algum modo à nomeação dos membros de seu organismo. A condução do órgão central para tal elo de união que possa gozar de mútua confiança e estima, para ser um fator que possa preencher com sucesso o interêsse público como um todo, depende finalmente da escolha feliz de pessoal.

V. Merikosky - Professor de Direito Administrativo da Universidade de Helsinki. UDC 378.1 (in "Revue Internationale des Sciences Administratives", vol. XXXIII, n 1, 1967). Tradução do Professor Roberto Ianini. 